\title{
Changes in prevalence and causes of visual impairment and cataract surgical coverage in Nampula, Mozambique between 2011 and 2018: findings from two cross-sectional surveys
}

Emma Jolley ( $\nabla$ ejolley@sightsavers.org )

Sightsavers https://orcid.org/0000-0002-2388-3454

Mércia Cumaio

Sightsavers

Anselmo Vilanculos

Nampula Central Hospital

Izidine Hassan

Sightsavers

Kahaki Kimani

University of Nairobi

Kolawole Ogundimu

Sightsavers

Elena Schmidt

Sightsavers

Research article

Keywords: Visual impairment, prevalence, equity, Mozambique

Posted Date: July 1st, 2020

DOI: https://doi.org/10.21203/rs.3.rs-38740/v1

License: (c) (i) This work is licensed under a Creative Commons Attribution 4.0 International License. Read Full License 


\section{Abstract \\ Background}

Globally, there are few examples of repeated eye health surveys to assess changes in prevalence and causes of visual impairment, and service coverage over time. Two separate, unlinked rapid assessments of avoidable blindness (RAAB) were conducted in Nampula province, Mozambique in 2011 and 2018. This paper reports the observed changes and examines how the trends differ for males and females.

\section{Methods}

Standard RAAB methodology was used in both studies. Two-stage cluster sampling was used to generate random samples of adults aged over 50 years. Participants underwent a simplified visual acuity exam focusing on presenting and pinhole visual acuity (VA), a lens exam and posterior segment exam using a direct ophthalmoscope for all subjects with presenting VA $<6 / 18$. Data were analysed using Stata and logistic regression models were developed to assess changes.

\section{Results}

The 2011 study enrolled 3,050 people and examined $96.9 \%$ (2,954 people). The 2018 survey enrolled 4,191 people and examined $95.8 \%$ (4,015 people). Age and sex adjusted estimates of blindness decreased from $6.2 \%$ in 2011 to $4.5 \%$ in $2018(z=-2.21, p=0.028)$, severe visual impairment remained the same (2.6\% in 2011 and $2.7 \%$ in $2018, z=0.1, p=0.9)$ and moderate visual impairment increased (5.9\% in 2011 to $11.0 \%$ in $2018, z=5.78, p<0.001)$. Cataract surgical coverage was higher among males in both surveys (13.4\% among males vs $7.7 \%$ among females in 2011 , and $40.0 \%$ among males vs $19.4 \%$ among females in 2018) and the gender disparity grew between surveys.

\section{Conclusions}

Significant changes were observed in the eye health and service coverage between 2011 and 2018. An increase in the proportion of good visual acuity among operated eyes between the surveys is of note and may correspond with improvements made to the services provided in the province. Further improvements to services are required to improve access for women and people with moderate visual impairment.

\section{Background}

The World Report on Vision, 2019, highlights the lack of robust survey data as a key challenge to addressing eye conditions and visual impairment ( $\mathrm{VI})$, particularly in sub-Saharan Africa(1). Changing demographics and lifestyles mean that the number of people affected by eye conditions is rapidly increasing, but not necessarily in line with the capacity of the health system or health seeking 
behaviour(2). Up-to-date population-based survey data is key for planning eye care services and monitoring changes in the epidemiology of eye diseases. Repeated surveys that use the same methodology and measures are also important to track and measure progress of eye care response over time and ensure services remain geared towards the needs of the populations they serve $(3,4)$.

Key indicators of success for national blindness prevention programmes have been long understood to include prevalence and causes of visual impairment, as well as measures of coverage of services among the population, for example cataract surgical coverage (CSC) which describes the proportion of people who have received cataract surgery, divided by the population in need $(1,4-6)$. However, more recently, there is a move to examine service coverage beyond a crude measure such as CSC, and to account for the impact of health interventions on health outcomes. These discussions have led to the introduction of a concept of effective coverage of services, defined as the proportion of the population who have accessed the intervention AND have received the maximum possible health gain given the ideal quality, divided by the population in need of the intervention.(7) Of course, debate remains as to how to define quality, however, the general premise of moving beyond crude coverage ratios to a more nuanced representation of service provision is well accepted. Within eye health therefore, suggestions have been made to create the indicators of effective cataract surgical coverage, and effective refractive error coverage, to be used alongside the crude service coverage indicators. $(8,9)$

In addition to measuring these indicators in the population as a whole, it is important to understand how such measures differ between different sub-groups, men and women, rich and poor, urban and rural and those with and without disabilities $(8,10,11)$. Evidence exists to suggest that health needs and access to health services varies between different population sub-groups but often to different extents in different locations $(10,12,13)$.

The Sustainable Development Goal mantra of leaving no one behind, as well as renewed focus from WHO on achieving universal health coverage, mean that political pressure is greater than ever for governments to demonstrate that they are including all members of society in all they do, including health service provision. Population based surveys, including those focused on visual impairment, need to incorporate measures of equity, to ensure that results can be examined by different population subgroups $(1,8,10,14)$.

\section{Visual Impairment In Mozambique}

No national blindness study has ever been conducted in Mozambique although several sub-national level studies have been undertaken that focus on specific population groups or ocular conditions. Between 2012 and 2015, 96 surveys were conducted to map trachoma in 137 districts across the country including both trichiasis among people aged 15 years and above, and trachomatous inflammation-follicular among children aged 1-9 years(15). A Rapid Assessment of Refractive Error, Presbyopia, and Visual Impairment and Associated Quality of Life among people aged 15-50 years was conducted in Nampula province in 2015(16). Rapid assessments of avoidable blindness (RAAB) have been conducted among 
people aged over 50 years in Nampula province in 2011, Sofala province in 2012 and Inhambane province in 2016(17-19).

The 2011 RAAB in Nampula identified high prevalence of presenting bilateral blindness (6.2\%), with cataract as the major cause (73.0\%). Coverage of cataract services were low $(10.3 \%)$, with women particularly disadvantaged as compared with men (7.7\% vs $12.8 \%)$. Importantly, visual acuity among operated people was poor, which, although not directly linked with surgical provision, can be considered a crude indicator that surgery was not providing the 'maximum possible health gain' for patients.

\section{Nampula Eye Care Programme, 2011-2018}

Following the dissemination of findings, The Nampula Eye Care Programme, delivered in partnership between The Ministry of Health and international non-governmental organisation (NGO) Sightsavers, prioritised activities to increase coverage with cataract services and improve visual outcomes of surgery by: introducing optical biometry and a keratometer in the main tertiary hospital and through outreaches in the district hospitals; training and deploying ophthalmic technicians to primary and secondary health facilities throughout the province; strengthening the community outreach programme to improve community education and increase screening services; introducing one week follow-up to deal with immediate complications; and introducing patient transport for surgical services. More recently, since 2016, the partnership has sought to improve the gender focus of the programme and has: increased the proportion of community health workers trained who are female; prioritised women for screening and treatment; sensitised staff to the additional and specific needs for both females and people living with disabilities; and introduced a standardised cataract monitoring tool to identify any poor results and implement improvements(20,21).

In 2018, the Nampula eye care programme conducted a second RAAB in Nampula province to measure changes since the 2011 study and realign programme activities according to the updated data. The objective of this paper is to report how the prevalence and causes of $\mathrm{VI}$, and crude and effective coverage of cataract services has changed between RAABs conducted in Nampula province in 2011 and 2018. We also sought to understand how the situation differed for men and women between 2011 and 2018.

\section{Methods}

Two separate, unlinked cross-sectional surveys were undertaken in Nampula province, Mozambique. The first survey was undertaken in August 2011, and the second survey was undertaken in August and September 2018. Both used the standardised RAAB methodology which has been well described elsewhere(22).

The major objectives of both studies were to determine the prevalence of visual impairment among people aged 50 years or above; determine the causes of visual impairment; and to determine the coverage with cataract surgical services of people living in Nampula province. 


\section{Sampling}

Sampling methodology was similar in both surveys and followed standard RAAB methodology. The primary sampling unit was people aged 50 years and above who lived in sampled clusters and households. Two-stage sampling was conducted that entailed probability proportional-to-size (PPS) to select enumeration units followed by compact segment sampling (CSS) within enumeration units to select households. PPS sampling was conducted for both surveys by constructing a list of all enumeration units in the province using 2007 census data obtained from the National Institute of Statistics (Instituto Nacional De Estatistica). Population size was listed alongside the name of the unit and was uploaded with the RAAB software to select the required number of clusters. CSS was conducted within the selected enumeration units if they were particularly large, i.e. if it could be expected that at least twice as many people as we hoped to enumerate aged over 50 years would live there (i.e. at least 100 in 2011 and at least 80 in 2018). The CSS was conducted prior to the visit by the enumeration team and was done collaboratively between the cluster informer and local leader to ensure the rationale for selecting only part of the area to participate in the survey was well understood.

Sample size calculations were made for both surveys using the calculator built in to the RAAB software. In 2011 the sample size was calculated to be 3,050 people, or 61 clusters of 50 people. This was based on an expected prevalence of blindness in adults aged over 50 years of $5.0 \%$, a precision of $20 \%$ (i.e. worst acceptable result of $4.0 \%$ ), $95 \%$ confidence intervals, with a design effect of 1.5 for clusters of 50 people, and $10 \%$ non-response.

In 2018 the sample size was calculated to be 4,200 people, or 105 clusters of 40 people. This was based on an expected prevalence of blindness in adults aged over 50 years of $5.0 \%, 95 \%$ confidence, a precision of $16 \%$ (i.e. worst acceptable result of $4.2 \%$ ), with a design effect of 1.4 for clusters of 40 people, and $5 \%$ non-response. The $5 \%$ non-response rate and clusters of size 40 were chosen for this survey due to recent experiences of conducting trachoma surveys in the area which yielded high response rates but long travel times between and within clusters.

\section{Inclusion and exclusion criteria}

People eligible to participate in the survey were people aged 50 years or above who had been resident in the household for the past six months. People aged under 50 years or who were newly resident or only visiting were ineligible. People normally eligible but absent on the day the study team visited were enrolled but not examined and basic details on their visual status were gathered from their families or neighbours.

\section{Enrolment and examination procedures}

RAAB study teams in both surveys consisted of either an ophthalmologist and ophthalmic technician or two ophthalmic technicians. In both cases, all team members underwent a one-week standardised training course by a RAAB certified trainer and successfully passed an intra-observer variation test, for 
which the minimum acceptable kappa scores was 0.6 over nine indicators. In 2011 there were four teams and 2018 there were five teams collecting data.

Study procedures were the same in both surveys. A cluster informer travelled a day or two ahead of the RAAB study team to each enumeration unit to meet the community leader and inform them about the study. If the community was large they would conduct a CSS exercise to select a smaller portion of the community for the RAAB study team to visit.

Once at a house, the study team introduced themselves to the head of the household and ascertained whether any residents were eligible for participation in the study. Eligible participants were given information about the study and consent was sought. A presenting visual acuity (VA) examination was undertaken, with spectacles if available, outside the house using a simplified 'E' optotype according to standard RAAB procedure. Participants with VA $<6 / 18$ in either eye were re-examined using a pinhole occlude to ascertain their best corrected visual acuity. All participants underwent a lens examination in a darkened location (normally inside their house) to determine whether the lens was normal, occluded, aphakic, pseudoaphakic with or without posterior capsule opacification, or not visible at all. All eyes with presenting $V A<6 / 18$ were then assigned a primary cause of visual impairment, with the study team undertaking an examination of the posterior segment if necessary. Participants with unoperated cataract were asked reasons for not having sought care. Participants who had been previously operated for cataract were asked for details of their operation(s).

\section{Population data}

Population data used for the 2011 survey was taken from the 2007 census, and for the 2018 survey was from the 2017 census. 
Table 1

Distributions of Nampula population by age and sex from 2007 and 2017 censuses

\begin{tabular}{|lllllll|}
\hline & Males & \multicolumn{3}{c}{ Females } & \multicolumn{3}{l|}{ Total } \\
\cline { 2 - 7 } & $\mathbf{n}$ & $\%$ & $\mathbf{n}$ & $\%$ & $\mathbf{n}$ & $\%$ \\
\hline 2017 census & & & & & & \\
\hline $50-59$ years & 88,291 & $49.7 \%$ & 87,587 & $54.3 \%$ & 175,878 & $51.9 \%$ \\
\hline $60-69$ years & 53,307 & $30.0 \%$ & 47,032 & $29.2 \%$ & 100,339 & $29.6 \%$ \\
\hline $70-79$ years & 25,315 & $14.3 \%$ & 19,047 & $11.8 \%$ & 44,362 & $13.1 \%$ \\
\hline $80-99$ years & 10,564 & $6.0 \%$ & 7,543 & $4.7 \%$ & 18,107 & $5.3 \%$ \\
\hline Total & 177,477 & $100.0 \%$ & 161,209 & $100.0 \%$ & 338,686 & $100.0 \%$ \\
\hline 2017 census & & & & & & \\
\hline $50-59$ years & 112,292 & $48.8 \%$ & 106,864 & $48.7 \%$ & 219,156 & $48.8 \%$ \\
\hline $60-69$ years & 66,816 & $29.1 \%$ & 63,828 & $29.1 \%$ & 130,644 & $29.1 \%$ \\
\hline $70-79$ years & 32,083 & $13.9 \%$ & 30,169 & $13.8 \%$ & 62,252 & $13.9 \%$ \\
\hline $80-99$ years & 18,812 & $8.2 \%$ & 18,348 & $8.4 \%$ & 37,160 & $8.3 \%$ \\
\hline Total & 230,003 & $100.0 \%$ & 219,209 & $100.0 \%$ & 449,212 & $100.0 \%$ \\
\hline
\end{tabular}

Study definitions were as follows: 


\begin{tabular}{|c|c|}
\hline Blindness & VA $<3 / 60$ in the better eye with available correction (presenting VA) \\
\hline Severe VI & $V A<6 / 60-3 / 60$ in the better eye with available correction \\
\hline Moderate VI & $V A<6 / 18-6 / 60$ in the better eye with available correction \\
\hline $\begin{array}{l}\text { Good visual outcome } \\
\text { in operated eye }\end{array}$ & $V A \geq 6 / 18$ in operated eye \\
\hline Borderline & $V A \geq 6 / 60$ but $<6 / 18$ in operated eye \\
\hline Poor & $V A<6 / 60$ in operated eye \\
\hline $\begin{array}{l}\text { Cataract surgical } \\
\text { coverage (persons) } \\
\text { (5) }\end{array}$ & $\begin{array}{l}\frac{x+y}{x+y+z} \times 100 \\
\text { Where } \\
x=\text { persons with unilateral (pseudo)aphakia and an operable cataract in the } \\
\text { other eye, } \\
y=\text { persons with bilateral (pseudo) aphakia, and } \\
z \text { = persons with bilateral operable cataract }\end{array}$ \\
\hline $\begin{array}{l}\text { Effective cataract } \\
\text { surgical coverage } \\
\text { (persons)(8) }\end{array}$ & $\begin{array}{l}\frac{c+d}{x+y+z} x 100 \\
\text { Where } \\
c=\text { individuals with unilateral pseudo/aphakia achieving presenting visual } \\
\text { acuity of } 6 / 18 \text { or better in the operated eye and operable cataract in the } \\
\text { other eye } \\
d=\text { individuals with bilateral pseudo/aphakia achieving presenting visual } \\
\text { acuity of } 6 / 18 \text { or better in at least one eye } \\
\text { and } x, y \text {, and } z \text { are as above }\end{array}$ \\
\hline
\end{tabular}

\section{Data analysis}

For both surveys, data analysis was carried out by the RAAB software which produces comprehensive standard tables addressing sample and age and sex adjusted prevalence of visual impairment, causes of visual impairment, cataract surgical coverage, quality of visual outcomes, reasons for poor visual outcomes, and barriers to cataract surgery. We assessed differences between measures in the two surveys and between males and females using logistic regression models developed using Stata v15 statistical software(23). The models examined associations, presented as odds ratios, between the binary outcome measures (blind, Severe $\mathrm{Vl}$, Moderate $\mathrm{VI}$ ) and the independent variables described adjusted for clustering and age and sex differences. We used p-values to assess whether the observed differences in odds ratios reported in the model were likely to have occurred by chance, using the standard 1 in 20 ( $p=$ 0.05) as an indicator of whether the association was likely to have occurred by chance. 


\section{Ethics}

Both studies were conducted in line with the principles of ethical conduct of research and were granted ethical approval by the Mozambique National Bioethics Committee prior to collecting data.

In both 2011 and 2018, participants were given oral information about the study and provided with an opportunity to ask questions. It was stressed that participation was entirely voluntary, and written consent was taken with adaptations for those who were illiterate or had other impairments preventing them from signing their own name. Participants examined and found to have ocular morbidities were either treated on site, given referral to the nearest health facility with required services, or asked for permission to share their name with the team recorder to ensure they would be transported to Nampula Central Hospital at the next available time.

\section{Results}

Table 2 shows the response status of participants by sex. The 2011 study enrolled 3,050 people and examined $96.9 \%$ (2,954 people). The 2018 survey enrolled 4,191 people and examined $95.8 \%(4,015$ people). Women accounted for $45.6 \%$ of those examined in the 2011 survey and $45.3 \%$ of those examined in the 2018 survey.

In 2011, very few people who were not examined were absent from home (0.6\%) compared with those who refused or were unable to participate (2.5\%). In 2018, the reasons for not being examined were more evenly split between those absent from home (2.2\%) and those who refused or were unable $(2.0 \%)$. 
Table 2

Sex distribution of respondents, by examination status

\begin{tabular}{|c|c|c|c|c|c|c|c|c|}
\hline \multicolumn{9}{|c|}{2011 survey } \\
\hline & \multicolumn{2}{|c|}{ Examined } & \multicolumn{2}{|c|}{ Absent } & \multicolumn{2}{|c|}{ Refused/ unable } & \multicolumn{2}{|l|}{ Total } \\
\hline & $\mathrm{n}$ & $\%$ & $\mathrm{n}$ & $\%$ & $\mathrm{n}$ & $\%$ & $\mathbf{n}$ & $\%$ \\
\hline Males & 1,347 & 97.0 & 13 & 0.9 & 28 & 2.0 & 1,388 & 100 \\
\hline Females & 1,607 & 96.7 & 6 & 0.4 & 49 & 2.9 & 1,662 & 100 \\
\hline Total & 2,954 & 96.9 & 19 & 0.6 & 77 & 2.5 & 3,050 & 100 \\
\hline \multicolumn{9}{|c|}{2018 survey } \\
\hline & \multicolumn{2}{|c|}{ Examined } & \multicolumn{2}{|c|}{ Absent } & \multicolumn{2}{|c|}{ Refused/ unable } & \multicolumn{2}{|l|}{ Total } \\
\hline & $\mathrm{n}$ & $\%$ & $\mathrm{n}$ & $\%$ & $\mathrm{n}$ & $\%$ & n & $\%$ \\
\hline Males & 1,819 & 95.4 & 50 & 2.6 & 37 & 1.9 & 1,906 & 100 \\
\hline Females & 2,196 & 96.1 & 42 & 1.8 & 47 & 2.1 & 2,285 & 100 \\
\hline Total & 4,015 & 95.8 & 92 & 2.2 & 84 & 2.0 & 4,191 & 100 \\
\hline
\end{tabular}

\section{Prevalence Of Visual Impairment}

The sample prevalence of bilateral blindness, shown in Table 3, was significantly lower in 2018 than 2011 ( $7.1 \%$ in 2011 vs $4.7 \%$ in $2018, z=-4.39, p<0.001)$. Sample prevalence of severe VI remained similar between the two surveys ( $3.1 \%$ in 2011 vs $2.8 \%$ in $2018, z=-0.51, p=0.6$ ), and sample prevalence of moderate VI increased significantly $(6.5 \%$ in 2011 vs $11.3 \%$ in $2018, z=6.71, p<0.001)$. 
Table 3

Sample prevalence of visual impairment in 2011 and 2018 surveys

\begin{tabular}{|c|c|c|c|c|c|c|}
\hline \multicolumn{7}{|l|}{2011 survey } \\
\hline & \multicolumn{2}{|c|}{ Males } & \multicolumn{2}{|c|}{ Females } & \multicolumn{2}{|c|}{ Total } \\
\hline & $\mathbf{n}$ & $\%$ & $\mathbf{N}$ & $\%$ & $\mathrm{n}$ & $\%$ \\
\hline & & $95 \% \mathrm{Cl}$ & & $95 \% \mathrm{Cl}$ & & $95 \% \mathrm{Cl}$ \\
\hline \multirow[t]{2}{*}{ Bilateral blindness } & 92 & $6.8 \%$ & 119 & $7.4 \%$ & 211 & $7.1 \%$ \\
\hline & & $5.2-8.4$ & & $5.6-9.2$ & & $5.8-8.5$ \\
\hline \multirow[t]{2}{*}{ Bilateral severe VI } & 47 & $3.5 \%$ & 43 & $2.7 \%$ & 90 & $3.1 \%$ \\
\hline & & $2.4-4.5$ & & $1.9-3.5$ & & $2.4-3.7$ \\
\hline \multirow[t]{2}{*}{ Bilateral moderate VI } & 90 & $6.7 \%$ & 103 & $6.4 \%$ & 193 & $6.5 \%$ \\
\hline & & $5.1-8.2$ & & $5.2-7.6$ & & $5.5-7.6$ \\
\hline \multicolumn{7}{|l|}{2018 survey } \\
\hline \multirow[t]{2}{*}{ Bilateral blindness } & 76 & $4.2 \%$ & 111 & $5.1 \%$ & 187 & $4.7 \%$ \\
\hline & & $3.2-5.1$ & & $3.9-6.2$ & & $3.8-5.5$ \\
\hline \multirow[t]{2}{*}{ Bilateral severe VI } & 46 & $2.5 \%$ & 68 & $3.1 \%$ & 114 & $2.8 \%$ \\
\hline & & $1.7-3.3$ & & $2.4-3.8$ & & $2.3-3.4$ \\
\hline \multirow[t]{2}{*}{ Bilateral moderate VI } & 210 & $11.5 \%$ & 244 & $11.1 \%$ & 454 & $11.3 \%$ \\
\hline & & $10.1-13.0$ & & $9.4-12.8$ & & $10.1-12.5$ \\
\hline
\end{tabular}

After adjusting the results for age and sex structure of the population, Table 4, the prevalence of bilateral blindness in Nampula province decreased from $6.2 \%$ in 2011 to $4.5 \%$ in $2018(z=-2.21, p=0.028)$. The decrease in the prevalence of blindness was predominantly observed among males (6.1\% vs $3.8 \%$, $z=-2.61, p=0.01)$, and was not significant among females $(6.3 \%$ vs $5.3 \%, z=-1.04, p=0.3)$.

Bilateral severe VI remained almost the same at $2.6 \%$ in 2011 and $2.7 \%$ in $2018(z=0.1, p=0.9)$. A decrease was observed among males $(2.9 \%$ vs $2.4 \%, z=-1.07, p=0.3)$ and an increase among females $(2.2 \%$ vs $3.1 \%, z=1.4, p=0.2)$, although neither change was significant.

Bilateral moderate VI increased from 5.9\% in 2011 to $11.0 \%$ in $2018(z=5.78, p<0.001)$. Increases were observed among both males ( $6.3 \%$ vs $10.8 \%, z=3.94, p<0.001)$, and females $(5.5 \%$ vs $11.2 \%, z=5.29, p$ $<0.001)$. 
Table 4

Age and sex adjusted prevalence in 2011 and 2018 surveys

\begin{tabular}{|c|c|c|c|}
\hline \multicolumn{4}{|l|}{2011 survey } \\
\hline & Male & Female & Total \\
\hline & $\%$ & $\%$ & $\%$ \\
\hline & $95 \% \mathrm{Cl}$ & $95 \% \mathrm{Cl}$ & $95 \% \mathrm{Cl}$ \\
\hline \multirow[t]{2}{*}{ Bilateral blindness } & $6.1 \%$ & $6.3 \%$ & $6.2 \%$ \\
\hline & $4.5-7.7$ & $4.5-8.0$ & $4.8-7.5$ \\
\hline \multirow[t]{2}{*}{ Bilateral severe VI } & $2.9 \%$ & $2.2 \%$ & $2.6 \%$ \\
\hline & $1.9-4.0$ & $1.4-3.0$ & $1.9-3.3$ \\
\hline \multirow[t]{2}{*}{ Bilateral moderate VI } & $6.3 \%$ & $5.5 \%$ & $5.9 \%$ \\
\hline & $4.7-7.8$ & $4.3-6.6$ & $4.8-6.9$ \\
\hline \multicolumn{4}{|l|}{2018 survey } \\
\hline \multirow[t]{2}{*}{ Bilateral blindness } & $3.8 \%$ & $5.3 \%$ & $4.5 \%$ \\
\hline & $3.0-4.7$ & $4.2-6.6$ & $3.7-5.4$ \\
\hline \multirow[t]{2}{*}{ Bilateral severe VI } & $2.4 \%$ & $3.1 \%$ & $2.7 \%$ \\
\hline & $1.7-3.3$ & $2.4-4.0$ & $2.2-3.3$ \\
\hline \multirow[t]{2}{*}{ Bilateral moderate VI } & $10.8 \%$ & $11.2 \%$ & $11.0 \%$ \\
\hline & $9.5-12.2$ & $9.6-13.0$ & $9.9-12.2$ \\
\hline
\end{tabular}

\section{Causes Of Visual Impairment}

The proportion of bilateral blindness due to cataract decreased from $73 \%$ in 2011 to $56 \%$ in 2018 , Table 5. Cataract was responsible for similar levels of severe VI in both surveys: $68.9 \%$ in 2011 and $68.4 \%$ in 2018. The proportion of bilateral moderate VI due to cataract increased from $36.3 \%$ in 2011 to $43.2 \%$ in 2018. Glaucoma increased as a major cause of bilateral blindness from $9 \%$ in 2011 to $20 \%$ in 2018, and also appeared to be responsible for more severe $\mathrm{VI}$, increasing from $2-7 \%$, and moderate $\mathrm{VI}$ from $1-3.1 \%$. Refractive error was an insignificant cause of blindness in both surveys (0.9\% in 2011 and $0.5 \%$ in 2018). It also remained fairly static as a cause of both severe and moderate VI between 2011 (Severe VI 15.6\%; Moderate VI 43.5\%) and 2018 (Severe VI 16.7\%; Moderate VI 46.3\%). Other causes of VI at all levels remained small and relatively similar in both surveys. 
Table 5

Causes of visual impairment in 2011 and 2018 surveys

\section{1 survey}

\begin{tabular}{|lllllll|}
\hline & \multicolumn{2}{l}{ Blindness } & \multicolumn{2}{l}{ Severe VI } & \multicolumn{2}{l|}{ Moderate VI } \\
\hline & $\mathbf{N}$ & $\%$ & $\mathbf{N}$ & $\%$ & $\mathbf{N}$ & $\%$ \\
\hline Refractive error & 2 & $0.9 \%$ & 14 & $15.6 \%$ & 84 & $43.5 \%$ \\
\hline Uncorrected aphakia & 0 & 0 & 0 & 0 & 2 & $1.0 \%$ \\
\hline Unoperated cataract & 154 & $73.0 \%$ & 62 & $68.9 \%$ & 70 & $36.3 \%$ \\
\hline Trachomatous corneal opacity & 4 & $1.9 \%$ & 0 & 0 & 1 & $0.5 \%$ \\
\hline Non-trachomatous corneal opacity & 5 & $2.4 \%$ & 0 & 0 & 4 & $2.1 \%$ \\
\hline Phthisis & 0 & 0 & 0 & 0 & 0 & 0 \\
\hline Glaucoma & 19 & $9.0 \%$ & 2 & $2.2 \%$ & 2 & $1.0 \%$ \\
\hline ARMD & 2 & $0.9 \%$ & 1 & $1.1 \%$ & 2 & $1.0 \%$ \\
\hline Other posterior segment/ globe diseases & 25 & $11.8 \%$ & 11 & $12.2 \%$ & 28 & $14.5 \%$ \\
\hline 2018 survey & & & & & 14 & \\
\hline Refractive error & 1 & $0.5 \%$ & 19 & $16.7 \%$ & 210 & $46.3 \%$ \\
\hline Uncorrected aphakia & 0 & 0 & 0 & 0 & 0 & 0 \\
\hline Unoperated cataract & 104 & $55.6 \%$ & 78 & $68.4 \%$ & 196 & $43.2 \%$ \\
\hline Trachomatous corneal opacity & 3 & $1.6 \%$ & 1 & $0.9 \%$ & 0 & 0 \\
\hline Non-trachomatous corneal opacity & 9 & $4.8 \%$ & 0 & 0 & 2 & $0.4 \%$ \\
\hline Phthisis & 6 & $3.2 \%$ & 0 & 0 & 1 & $0.2 \%$ \\
\hline Glaucoma & 38 & $20.3 \%$ & 8 & $7.0 \%$ & 14 & $3.1 \%$ \\
\hline ARMD & 1 & $0.5 \%$ & 2 & $1.8 \%$ & 1 & $0.2 \%$ \\
\hline Other posterior segment/ globe diseases & $22.8 \%$ & 6 & $5.3 \%$ & 27 & $5.9 \%$ \\
\hline
\end{tabular}

\section{Post-surgical Visual Outcomes}

Visual outcomes among eyes operated for cataract improved between the two surveys, Table 6. In 2011, $34.6 \%$ of operated eyes had good presenting vision, i.e. they could see $6 / 18$, increasing to $57.7 \%$ with a pinhole. In $2018,58.2 \%$ of eyes had good presenting vision, increasing to $72.4 \%$ using a pinhole. The proportion of eyes with 'poor' presenting vision, i.e. they could not see $6 / 60$, was $26.9 \%$ in $2011(23.1 \%$ 
with pinhole) and decreased to $22.4 \%$ (16.3\% with pinhole) by 2018 . Very few eyes, three in each study, had an operation without an intraocular lens.

Table 6

Visual outcomes after cataract surgery in 2011 and 2018 surveys

\begin{tabular}{|c|c|c|c|c|c|c|}
\hline \multicolumn{7}{|l|}{2011 study } \\
\hline & \multicolumn{2}{|c|}{ Non-IOL } & \multicolumn{2}{|l|}{ IOL } & \multicolumn{2}{|l|}{ Total } \\
\hline & Eyes & $\%$ & Eyes & $\%$ & Eyes & $\%$ \\
\hline \multicolumn{7}{|c|}{ VA in operated eyes in sample with available correction (presenting) } \\
\hline Good: can see $6 / 18$ & 0 & 0.0 & 9 & 39.1 & 9 & 34.6 \\
\hline Borderline: can see $6 / 60$ & 2 & 66.7 & 8 & 34.8 & 10 & 38.5 \\
\hline Poor: cannot see $6 / 60$ & 1 & 33.3 & 6 & 26.1 & 7 & 26.9 \\
\hline \multicolumn{7}{|c|}{ VA in operated eyes in sample with best correction (pinhole) } \\
\hline Good: can see $6 / 18$ & 1 & 33.3 & 14 & 60.9 & 15 & 57.7 \\
\hline Borderline: can see $6 / 60$ & 1 & 33.3 & 4 & 17.4 & 5 & 19.2 \\
\hline Poor: cannot see $6 / 60$ & 1 & 33.3 & 5 & 21.7 & 6 & 23.1 \\
\hline Total & 3 & 100.0 & 23 & 100.0 & 26 & 100.0 \\
\hline \multicolumn{7}{|l|}{2018 study } \\
\hline \multicolumn{7}{|c|}{ VA in operated eyes in sample with available correction (presenting) } \\
\hline Good: can see $6 / 18$ & 0 & 0.0 & 57 & 60.0 & 57 & 58.2 \\
\hline Borderline: can see $6 / 60$ & 0 & 0.0 & 19 & 20.0 & 19 & 19.4 \\
\hline Poor: cannot see $6 / 60$ & 3 & 100.0 & 19 & 20.0 & 22 & 22.4 \\
\hline \multicolumn{7}{|c|}{ VA in operated eyes in sample with best correction (pinhole) } \\
\hline Good: can see $6 / 18$ & 0 & 0.0 & 71 & 74.7 & 71 & 72.4 \\
\hline Borderline: can see $6 / 60$ & 0 & 0.0 & 11 & 11.6 & 11 & 11.2 \\
\hline \multirow[t]{2}{*}{ Poor: cannot see $6 / 60$} & 3 & 100.0 & 13 & 13.7 & 16 & 16.3 \\
\hline & 3 & 100.0 & 95 & 100.0 & 98 & 100.0 \\
\hline
\end{tabular}

\section{Cataract Surgical Coverage}

Cataract surgical coverage among persons increased between 2011 and 2018, with coverage among males being uniformly higher than among females in both surveys and at all VA levels, Table 7. At VA< 
3/60 CSC increased from 10.1-28.4\%, with CSC among males increasing three-fold from $13.4-40.0 \%$ and CSC among females increasing 2.5-fold from 7.7-19.4\%. At VA $<6 / 60$, CSC increased from $8.2 \%$ in 2011 to $21.3 \%$ in 2018 and at VA<6/18 CSC increased from $6.4 \%$ in 2011 to $12.1 \%$ in 2018.

Effective cataract surgical coverage also increased between 2011 and 2018. In 2011, eCSC was very low at all levels of visual acuity and for males and females. It increased from $4.4 \%$ in 2011 to $18.9 \%$ in 2018 at the VA $<3 / 60$ level with males experiencing a greater increase (4.5-29.1\%) than females (4.4$11.1 \%)$. Similar patterns were observed at the other levels of visual acuity.

Table 7

Adjusted cataract surgical coverage (persons) and effective cataract surgical coverage (persons) in 2011 and 2018 surveys

\begin{tabular}{|c|c|c|c|}
\hline \multicolumn{4}{|c|}{2011 survey } \\
\hline & $V A<3 / 60$ & $V A<6 / 60$ & $V A<6 / 18$ \\
\hline \multicolumn{4}{|c|}{ Cataract surgical coverage $\%$} \\
\hline Total & 10.1 & 8.2 & 6.4 \\
\hline Male & 13.4 & 11.2 & 8.5 \\
\hline Female & 7.7 & 5.9 & 4.8 \\
\hline \multicolumn{4}{|c|}{ Effective cataract surgical coverage \% } \\
\hline Total & 4.4 & 3.4 & 2.5 \\
\hline Male & 4.5 & 3.4 & 2.6 \\
\hline Female & 4.4 & 3.4 & 2.4 \\
\hline \multicolumn{4}{|c|}{2018 survey } \\
\hline \multicolumn{4}{|c|}{ Cataract surgical coverage $\%$} \\
\hline Total & 28.3 & 21.3 & 12.1 \\
\hline Male & 40.0 & 30.7 & 19.5 \\
\hline Female & 19.4 & 14.1 & 7.0 \\
\hline \multicolumn{4}{|c|}{ Effective cataract surgical coverage \% } \\
\hline Total & 18.9 & 14.4 & 7.4 \\
\hline Male & 29.1 & 22.7 & 12.2 \\
\hline Female & 11.1 & 8.1 & 4.1 \\
\hline
\end{tabular}


Between 2011 and 2018 the prevalence of blindness decreased, severe visual impairment remained the same and prevalence of moderate visual impairment increased. Although the proportion of blindness due to cataract has reduced, it remains a very important cause at all levels of visual impairment. Refractive error remains an important cause of $\mathrm{VI}$, but posterior segment diseases appear to be increasing in importance.

Age and sex adjusted estimates of prevalence indicated relative equality between males and females in 2011 with $6.1 \%(95 \% \mathrm{Cl} 4.5-7.7 \%)$ of males bilaterally blind compared with $6.3 \%$ (95\% Cl $4.5-8.0 \%)$ of females. However, in 2018 we observed a non-statistically significant difference favouring males: $3.8 \%$ (95\% Cl 3.0-4.7) compared with 5.3\% (95\% Cl 4.2-6.6\%).

Although coverage and effective coverage of cataract services vastly improved between 2011 and 2018, they remain low. Cataract surgical coverage was significantly lower for women with no statistically demonstrable improvement observed overtime, although the relatively small number of surgeries observed may have undermined our ability to measure this change. However, the data indicates a worrying trend towards increased, rather than decreased equality of outcomes for males and females, and indicates further effort is required to identify effective strategies to improve equity of access for females. This finding is in line from other research from sub-Saharan Africa and further afield $(10,12,24$, 25).

The focus made by the Nampula eye care team after the 2011 RAAB in reducing cataract blindness and improving visual outcomes was broadly successful. However, the focus appears to have been primarily on patients who were blind, making little difference for people affected by early stage visual impairment from cataract. This focus is not surprising given that the capacity of services available remain limited compared to the relatively large size of the province with most districts receiving only intermittent surgical provision through the use of eye camps. Regular surgical services are available only at Nampula central hospital in the provincial capital. Surgical services delivered through camps rather than permanent services may reach predominantly blind patients for a number of reasons including they are more easily identified through community-based screening activities and they may be more willing to undergo the waiting time associated with visiting surgeons(26). Surgical services delivered through such camps may also exacerbate differences related to gender and poverty such as ability to leave the home and associated responsibilities in order to attend the camp(27).

Planning based on the 2018 survey should review how eye care services in Nampula province can be scaled up to address all causes and levels of VI. There is also a need to develop strategies to reach population areas and population sub-groups which are left further behind, and particularly women. Future research and population-based surveys should consider capturing standardised indicators of equity, such as those recommended on the PROGRESS checklist to support better inclusion of equity data in such studies $(24,28)$. The routine addition of data such as: Place of residence; Race/ethnicity/ culture/ language; Occupation; Gender/sex; Religion; Education; Socioeconomic status; Social capital/ networks, 
would support better localised planning, which is vitally important in resource constrained environments such as Nampula as well as reporting against global targets such as the sustainable development goals.

This study is subject to several limitations. In particular, the RAAB methodology itself is relatively limited in terms of determining specific causes of $\mathrm{VI}$, for example posterior segment diseases, and cannot tell us about magnitude or trends of visual impairment in younger age groups and children.(22) RAAB requires examiners to determine only the one most likely cause of VI and so cannot tell us anything about comorbidity which is likely among older participants. RAABs are powered to calculate the prevalence of blindness in a study site and may not sample enough participants to reliably measure the differences between population sub-groups.

\section{Conclusions}

This study highlights the importance of repeated surveys to understand progress and trends within district eye health programmes. The different results for males and females highlight the variation that can occur between sub-groups and underlines the needs to investigate other characteristics, for example disability, poverty and location. This study shows that improvements can be made in tackling avoidable blindness in an extremely underserved area. However, challenges around coverage and equity of services remain and the challenge for health planners and implementers must shift to address these issues.

\section{List Of Abbreviations}

ARMD Age related macular degeneration

Cl Confidence interval

CSC Cataract surgical coverage

CSR Cataract surgical rate

CSS Compact segment sampling

ECSC Effective cataract surgical coverage

IOL Intra-ocular lens

IOV Inter-observer variation

PPS Probability proportionate to size

RAAB Rapid assessment of avoidable blindness

VA Visual acuity

Page 17/21 


\section{Declarations}

\section{Consent for publication}

Not applicable

\section{Availability of data and materials}

The datasets used and/or analysed during the current study are available from the corresponding author on reasonable request.

\section{Competing interests}

The authors declare that they have no competing interests.

\section{Funding}

2011 - Sightsavers.

2018 - UKAID Match, UK Department for International Development.

DFID had no role in any part of the study. Several Sightsavers staff had roles in both studies, as detailed below.

\section{Authors' contributions}

EJ made significant contributions to the design of the 2018 study, acquisition of 2018 data, analysis and interpretation of 2011 and 2018 results, and drafted this manuscript.

MCumaio made significant contributions to the design of the 2011 and 2018 studies, acquisition of 2011 and 2018 data and intrepretation of 2011 and 2018 results.

AV made significant contributions to the design of the 2011 and 2018 studies, acquisition of 2018 data and intrepretation of 2011 and 2018 results.

IH made significant contributions to the design of the 2011 and 2018 studies, and intrepretation of 2011 and 2018 results.

KK made significant contributions to the design of the 2011 study, acquisition of 2011 data, analysis and interpretation of 2011 results. 
KO made significant contributions to the design of the 2018 study, acquisition of 2018 data, interpretation of 2018 results, and substantively revised this manuscript.

ES made significant contributions to the interpretation of 2011 and 2018 results, and substantively revised this manuscript.

ALL authors have approved the submitted version of this manuscript AND have agreed both to be personally accountable for the author's own contributions and to ensure that questions related to the accuracy or integrity of any part of the work, even ones in which the author was not personally involved, are appropriately investigated, resolved, and the resolution documented in the literature.

\section{Acknowledgements}

The authors acknowledge the support of Abrão Banqueiro Chale and Dr Stevens Bechange for the planning and implementation of the 2018 study. We thank Dr Margarida Chagunda for her support to both studies. Both studies took place thanks to the hard work of the data collectors: the ophthalmologists, ophthalmic technicians, cluster informers and drivers who went throughout in Nampula to collect the data - thank you.

\section{References}

1. World Health Organization. World report on vision. Geneva; 2019.

2. Bourne RR, Flaxman SR, Braithwaite T, Cicinelli MV, Das A, Jonas JB, et al. Magnitude, temporal trends, and projections of the global prevalence of blindness and distance and near vision impairment: a systematic review and meta-analysis. Lancet Glob Health. 2017;5(9):e888-e97.

3. Marmamula S, Keeffe JE, Rao GN. Rapid assessment methods in eye care: an overview. Indian J Ophthalmol. 2012;60(5):416-22.

4. World Health Organization. Universal Eye Health: A global action plan 2014-2019 Geneva;; 2013.

5. Limburg H, Foster A. Cataract surgical coverage: an indicator to measure the impact of cataract intervention programmes. Community Eye Health. 1998;11(25):3.

6. Gray Z, Ackland P. Cataract surgical coverage. IAPB; 2015.

7. Jannati A, Sadeghi V, Imani A, Saadati M. Effective coverage as a new approach to health system performance assessment: a scoping review. BMC Health Services Research. 2018;18(1):886.

8. Ramke J, Gilbert CE, Lee AC, Ackland P, Limburg H, Foster A. Effective cataract surgical coverage: An indicator for measuring quality-of-care in the context of Universal Health Coverage. PLoS One. 2017;12(3):e0172342.

9. McCormick I, Mactaggart I, Bastawrous A, Burton MJ, Ramke J. Effective refractive error coverage: an eye health indicator to measure progress towards universal health coverage. Ophthalmic Physiol Opt. 2020;40(1):1-5. 
10. Jolley E, Buttan S, Engels T, Gillani M, Jadoon MZ, Kabona G, et al. Prevalence of Visual Impairment and Coverage of Cataract Surgical Services: Associations with Sex, Disability, and Economic Status in Five Diverse Sites. Ophthalmic Epidemiology. 2020:1-9.

11. Ramke J, Gilbert CE. Universal eye health: are we getting closer? Lancet Glob Health. 2017;5(9):e843e4.

12. Lewallen S, Mousa A, Bassett K, Courtright P. Cataract surgical coverage remains lower in women. Br J Ophthalmol. 2009;93(3):295-8.

13. Mohanty S, Jolley E, Mohanty R, Buttan S, Schmidt E. Integrating Geospatial Data and Measures of Disability and Wealth to Assess Inequalities in an Eye Health Survey: An Example from the Indian Sunderbans. Int J Environ Res Public Health. 2019;16(23):4869.

14. Mactaggart I, Wallace S, Ramke J, Burton M, Bastawrous A, Limburg H, et al. Rapid assessment of avoidable blindness for health service planning. Bull World Health Organ. 2018;96(10):726.

15. Abdala M, Singano CC, Willis R, Macleod CK, Backers S, Flueckiger RM, et al. The Epidemiology of Trachoma in Mozambique: Results of 96 Population-Based Prevalence Surveys. Ophthalmic Epidemiol. 2018;25(sup1):201-10.

16. Loughman J, Nxele LL, Faria C, Thompson S, Ramson P, Chinanayi F, et al. Rapid Assessment of Refractive Error, Presbyopia, and Visual Impairment and Associated Quality of Life in Nampula, Mozambique. Journal of Visual Impairment Blindness. 2015;109(3):199-212.

17. Kimani K. Rapid Assessment of Avoidable Blindness (RAAB) Nampula Province, Mozambique. Sightsavers International. 2011.

18. Chagunda M, Roba A, Machissa T. Rapid Assessment of Avoidable Blindness in Sofala Province of Mozambique. Hospital Central da Beira. 2013.

19. Deon Minnies. Rapid assessment of avoidable blindness Inhambane province, Mozambique.; 2016.

20. Lindfield R, Vishwanath K, Ngounou F, Khanna RC. The challenges in improving outcome of cataract surgery in low and middle income countries. Indian J Ophthalmol. 2012;60(5):464.

21. ICEH. Monitoring cataract surgical outcomes. 2010.

22. Kuper H, Polack S, Limburg H. Rapid assessment of avoidable blindness. Community Eye Health. 2006;19(60):68-9.

23. Statacorp LLC. Stata. 15.1 ed2018.

24. Ramke J, Zwi AB, Palagyi A, Blignault I, Gilbert CE. Equity and Blindness: Closing Evidence Gaps to Support Universal Eye Health. Ophthalmic Epidemiol. 2015;22(5):297-307.

25. Ramke J, Petkovic J, Welch V, Blignault I, Gilbert C, Blanchet K, et al. Interventions to improve access to cataract surgical services and their impact on equity in low- and middle-income countries. Cochrane Database of Systematic Reviews. 2017(11).

26. Ubah JN, Isawumi MA, Adeoti C. Barriers to uptake of cataract surgery: An eye camp account. Research in Opthalmology. 2013;2(1):1-3. 
27. Bekibele CO, Murthy GVS. Barriers to cataract surgery of persons screened at camps in Ibadan, Nigeria. Afr J Med Med Sci. 2012;41(3):257-64.

28. O'Neill J, Tabish H, Welch V, Petticrew M, Pottie K, Clarke M, et al. Applying an equity lens to interventions: using PROGRESS ensures consideration of socially stratifying factors to illuminate inequities in health. J Clin Epidemiol. 2014;67(1):56-64. 